\title{
Resistance-Trained Individuals Are Less Susceptible to Oxidative Damage after Eccentric Exercise
}

\author{
Ypatios Spanidis, ${ }^{1}$ Dimitrios Stagos, ${ }^{1}$ Christina Papanikolaou, ${ }^{1}$ Konstantina Karatza, ${ }^{1}$ \\ Andria Theodosi, ${ }^{1}$ Aristidis S. Veskoukis, ${ }^{1}$ Chariklia K. Deli ${ }^{D},{ }^{2}$ Athanasios Poulios, ${ }^{2}$ \\ Sofia D. Koulocheri, ${ }^{3}$ Athanasios Z. Jamurtas $\mathbb{D}^{2},^{2}$ Serkos A. Haroutounian $\mathbb{D}^{3}{ }^{3}$ \\ and Demetrios Kouretas $\mathbb{D}^{1}$ \\ ${ }^{1}$ Laboratory of Animal Physiology, Department of Biochemistry and Biotechnology, University of Thessaly, 41500 Viopolis, \\ Larissa, Greece \\ ${ }^{2}$ Laboratory of Exercise Biochemistry, Exercise Physiology and Sports Nutrition (SmArT Lab), Department of Physical Education and \\ Sport Science, University of Thessaly, 42100 Trikala, Greece \\ ${ }^{3}$ Department of Nutritional Physiology and Feeding, Faculty of Animal Science and Aquaculture, Agricultural University of Athens, \\ Iera Odos 75, 11855 Athens, Greece
}

Correspondence should be addressed to Demetrios Kouretas; dkouret@uth.gr

Received 9 March 2018; Accepted 21 June 2018; Published 17 July 2018

Academic Editor: Joanna Lecka

Copyright (c) 2018 Ypatios Spanidis et al. This is an open access article distributed under the Creative Commons Attribution License, which permits unrestricted use, distribution, and reproduction in any medium, provided the original work is properly cited.

\begin{abstract}
It has been proposed that exercise-induced oxidative stress and adaptations are dependent on training status. In this study, we examined the effects of training background on free radical generation and adaptations after eccentric exercise. Forty volunteers were divided into two groups (trained and untrained) and were asked to perform eccentric exercise. Then, their blood samples were collected pre, 24, 48, and 72 hours postexercise. Biomarkers indicating oxidative damage and the antioxidant profiles of the participants were measured in plasma and erythrocyte lysate both spectrophotometrically and chromatographically. The results revealed that the untrained group depicted more severe oxidative damage (protein carbonyls, malondialdehyde), weaker antioxidant status (reduced glutathione, static and capacity oxidation-reduction potential), and weaker radical-scavenging activity (superoxide radical scavenging and reducing power) compared to the trained participants. Our findings show that trained individuals are less susceptible to oxidative damage and suggest that generalized nutritional recommendations regarding recovery after exercise should be avoided.
\end{abstract}

\section{Introduction}

The association between physical exercise and free radical generation has been established in the literature and is attributed to diverse mechanisms [1]. Numerous studies have reported that reactive oxygen species (ROS) generation postexercise leads to severe muscle damage and oxidative stress [2]. Moreover, it has been proposed that the magnitude of ROS production is directly related to exercise intensity, resulting therefore to an excessive increase in ROS production after an intense and demanding exercise [3].
Eccentric exercise is considered to be a quite demanding exercise modality. It is characterized by an active contraction and lengthening of skeletal muscle inducing severe tissue damage characterized by decreased muscle force production, increased serum creatine kinase activity, and inflammation [4]. Thus, eccentric exercise leads to cellular disruption, loss of normal function, and soreness [5]. However, despite the fact that eccentric exercise is related to severe oxidative stress induction, significant differences in oxidation levels after eccentric exercise, as well as the presence of reductive stress among individuals, have also been observed [6]. Such 
diversity could be possibly attributed to the training background of each individual, since, according to the literature, ROS produced during regular exercise induce adaptations by improving antioxidant capacity, mitochondrial biogenesis, insulin sensitivity, cytoprotection, and aerobic capacity of skeletal muscle [2].

Since there was a need to find a parameter that may affect individuals' response after performing eccentric exercise, the primary purpose of the present study was to examine the effects of muscle-damaging eccentric exercise on blood redox profile and to shed light on the impact of training load on redox adaptations. Furthermore, we attempted to clarify whether training background affects changes in redox biomarkers after an arduous and demanding exercise modality, such as eccentric exercise. The idea for the present study emerged from past works of our scientific team and others that correlated oxidative damage (protein carbonyls (PC), thiobarbituric acid reactive substances (TBARS)) and the weaker redox status of individuals with muscle soreness after bouts of eccentric exercise. In addition, the diversity among participants is highlighted [6-9].

It is evident that this approach will try to fill the gaps in literature regarding the response of trained and untrained people after performing eccentric exercise and examine whether an individual or group approach should be conducted. This would also help to improve the response of exercising individuals regarding recovery and health status after specific interventions (e.g., nutrition or administration of antioxidant supplements). We hypothesized that untrained people may display a compromised antioxidant profile and, therefore, will be more susceptible to oxidative and muscle damage compared to the trained ones as they are less adapted in performing bouts of exercise.

\section{Materials and Methods}

2.1. Subjects. Twenty-four male and sixteen female volunteers (age $22.5 \pm 0.58$ years, height $175.1 \pm 1.6 \mathrm{~cm}$, and weight $75.4 \pm 2.3 \mathrm{~kg}$ ) participated in the present study. The selection of the participants was based on their athletic (i.e., training) background. In order to cluster the participants into two groups, they were asked to provide details about their athletic background. According to them, the trained group consisted of 15 males and 7 females. Seventeen participants regularly performed resistance exercise (i.e., weightlifting) recreationally at least 4 times per week, while the remaining 5 mostly performed a combination of aerobic and resistance exercises. The untrained group comprised 18 participants (9 males and 9 females), who had never been in contact with any kind of exercise.

Subjects have not suffered any musculoskeletal injuries to the lower limbs that would limit their ability to perform the exercise protocol. Additionally, the participants were asked to abstain from smoking and from consuming alcohol and nutritional supplements, as well as from engaging in any kind of exercise for over a week before the study and during the experiment. However, there were no limitations regarding food intake before or during blood sampling. Body mass was measured to the nearest $0.5 \mathrm{~kg}$ (BeamBalance 710, Seca,
United Kingdom), while the subjects were lightly dressed and barefoot. Standing height was measured to the nearest $0.5 \mathrm{~cm}$ (Stadiometer 208, Seca). A written informed consent to participate in the study was provided to and was signed by all participants after they had been informed of all benefits, risks, and discomforts of the investigation.

2.2. Study Design. The participants of the present study were divided into two groups (i.e., trained and untrained) according to their athletic background, as mentioned in Section 2.1. Blood samples were collected before and $24 \mathrm{~h}, 48 \mathrm{~h}$, and $72 \mathrm{~h}$ after performing the eccentric exercise protocol described in the next paragraph. Plasma and erythrocyte lysate samples were isolated after blood collection and stored at $-80^{\circ} \mathrm{C}$ until the biochemical analyses were performed.

2.3. Eccentric Exercise Protocol. An eccentric exercise session was performed on an isokinetic dynamometer (Cybex Norm, Ronkonkoma, NY) and exercise protocols were undertaken from the seated position $\left(120^{\circ}\right.$ hip angle) with the lateral femoral condyle aligned with the axis of rotation of the dynamometer. Participants were coupled to the dynamometer by an ankle cuff, attached proximal to the lateral malleolus, and finally stabilized according to the manufacturer's instructions. Participants completed 5 sets of 15 eccentric maximal voluntary contractions (knee range, $0^{\circ}$ full extension to $90^{\circ}$ flexion) at an angular velocity of $60 \%$ s. A $2 \mathrm{~min}$ rest interval was used between sets and the total workout time was $15 \mathrm{~min}$. Before the exercise session, subjects performed a $10 \mathrm{~min}$ warmup consisting of cycling on a Monark cycle ergometer (Vansbro, Sweden) at $70-80 \mathrm{rpm}$ and $50 \mathrm{~W}$.

2.4. Blood Sample Preparation. The blood samples were drawn from a forearm vein in ethylenediaminetetraacetic acid (EDTA) and heparin tubes at four different time points, namely, before exercise and 24,48 , and $72 \mathrm{~h}$ postexercise. Subsequently, they were centrifuged $(1370 \mathrm{~g}, 10 \mathrm{~min}$, and $4^{\circ} \mathrm{C}$ ) and the supernatant (i.e., plasma) was collected. The remaining packed erythrocytes were lysed with $1: 1(v / v)$ distilled water $\left(\mathrm{dH}_{2} \mathrm{O}\right)$, inverted vigorously, and centrifuged $\left(4020 \mathrm{~g}, 15 \mathrm{~min}\right.$, and $\left.4^{\circ} \mathrm{C}\right)$. The supernatant, which is the erythrocyte lysate, was then collected. The plasma and erythrocyte lysate samples were then stored at $-80^{\circ} \mathrm{C}$ until further biochemical analysis.

2.5. Biochemical Analyses. PC were determined in plasma as described in a previous work of our team [10]. Briefly, $50 \mu \mathrm{l}$ of $20 \%$ trichloroacetic acid (TCA) was added to $50 \mu \mathrm{l}$ of plasma, and this mixture was incubated in an ice bath for $15 \mathrm{~min}$ and centrifuged $\left(15,000 \mathrm{~g}, 5 \mathrm{~min}\right.$, and $\left.4^{\circ} \mathrm{C}\right)$. The supernatant was discarded and $500 \mu \mathrm{l}$ of $10 \mathrm{mM} \mathrm{2,4-dinitro-}$ phenylhydrazine (in $2.5 \mathrm{~N} \mathrm{HCl}$ ) for the sample, or $500 \mu \mathrm{l}$ of $2.5 \mathrm{~N} \mathrm{HCl}$ for the blank, was added to the pellet. The samples were incubated in the dark at room temperature (RT) for $1 \mathrm{~h}$ with intermittent vortexing every $15 \mathrm{~min}$ and centrifuged $\left(15,000 \mathrm{~g}, 5 \mathrm{~min}\right.$, and $\left.4^{\circ} \mathrm{C}\right)$. The supernatant was discarded, and $1 \mathrm{ml}$ of $10 \%$ TCA was added. Then, the samples were vortexed and centrifuged $\left(15,000 \mathrm{~g}, 5 \mathrm{~min}\right.$, and $\left.4^{\circ} \mathrm{C}\right)$. The supernatant was discarded, and $1 \mathrm{ml}$ of ethanol-ethyl acetate 
mixture $(1: 1 v / v)$ was added. Then, the samples were vortexed and centrifuged $\left(15,000 \mathrm{~g}, 5 \mathrm{~min}\right.$, and $\left.4^{\circ} \mathrm{C}\right)$. This step was repeated twice. The supernatant was discarded, and $1 \mathrm{ml}$ of $5 \mathrm{M}$ urea $(\mathrm{pH}=2.3)$ was added. Then, the samples were vortexed and incubated at $37^{\circ} \mathrm{C}$ for $15 \mathrm{~min}$. The samples were then centrifuged $(15,000 \mathrm{~g}, 3 \mathrm{~min}$, and $4^{\circ} \mathrm{C}$ ), and the absorbance was monitored at $375 \mathrm{~nm}$. Total plasma protein was determined using Bradford's method via a standard curve of solutions with known bovine serum albumin concentrations.

For plasma malondialdehyde (MDA) assessment as a biomarker of lipid peroxidation, one spectrophotometric (TBARS) and one chromatographic (high-performance liquid chromatography with diode-array detector, HPLCDAD) method was applied. For TBARS determination, $100 \mu \mathrm{l}$ of plasma was mixed with $500 \mu \mathrm{l}$ of $35 \%$ TCA and $500 \mu \mathrm{l}$ of Tris- $\mathrm{HCl}(200 \mathrm{mM}, \mathrm{pH}=7.4)$ and incubated for $10 \mathrm{~min}$ at RT. A total of $1 \mathrm{ml}$ of $2 \mathrm{M}$ sodium sulfate $\left(\mathrm{Na}_{2} \mathrm{SO}_{4}\right)$ and $55 \mathrm{mM}$ thiobarbituric acid (TBA) (2.84 $\mathrm{g}$ of $\mathrm{Na}_{2} \mathrm{SO}_{4}$ and $0.08 \mathrm{~g}$ of TBA diluted in $10 \mathrm{ml}$ of $\mathrm{dH}_{2} \mathrm{O}$ ) was added and the samples were incubated at $95^{\circ} \mathrm{C}$ for $45 \mathrm{~min}$. The samples were cooled on ice for $5 \mathrm{~min}$, vortexed after adding $1 \mathrm{ml}$ of $70 \% \mathrm{TCA}$, and centrifuged $\left(15,000 \mathrm{~g}, 3 \mathrm{~min}\right.$, and $\left.20^{\circ} \mathrm{C}\right)$. Then, the absorbance of the supernatant was monitored at $530 \mathrm{~nm}$. TBARS concentration was calculated on the basis of the molar extinction coefficient of MDA [10].

Regarding plasma MDA determination by chromatography (HPLC-DAD), a method described by Spirlandeli et al., [11] was used. Briefly, $100 \mu \mathrm{l}$ of plasma was added to $700 \mu \mathrm{l}$ of $1 \%$ phosphoric acid and $200 \mu \mathrm{l}$ of $42 \mathrm{mM} \mathrm{TBA}$. The mixture was vortexed and heated for $40 \mathrm{~min}$ in a water bath at $100^{\circ} \mathrm{C}$. Afterwards, $250 \mu \mathrm{l}$ of the mixture was added to $250 \mu \mathrm{l}$ of $1 \mathrm{M}$ sodium hydroxide in methanol $(1: 6)$, centrifuged $\left(10,000 \mathrm{~g}, 5 \mathrm{~min}\right.$, and $\left.20^{\circ} \mathrm{C}\right)$, filtered through a Milli-RO 10 Plus and a Milli-Q Plus plant (final pore size $0.2 \mathrm{~mm}$; Millipore, Bedford, MA). Then, $20 \mu \mathrm{l}$ of the supernatant was injected in the HPLC apparatus at a flow rate of $1 \mathrm{ml} / \mathrm{min}$. The absorbance was monitored at $532 \mathrm{~nm}$. For the MDA standard curve, a stock solution of $100 \mu \mathrm{M}$ MDA was prepared in $0.01 \mathrm{mM} \mathrm{HCl}$. Dilutions from stock MDA solutions of $2-14 \mu \mathrm{M}$ were then performed. The same treatment described for plasma was used for the standard. The method was carried out by using a $5 \mu \mathrm{m}$ C18 reversephase column $(4.6 \mathrm{~mm} \times 250 \mathrm{~mm})$ in a Hewlett Packard HP1100 Series HPLC Value System (Agilent Technologies, Waldbronn, Germany) equipped with a quaternary pump, autosampler, degasser, and diode array detector (DAD). Retrieval and processing of chromatographic data was performed with Chemstation Software.

In total antioxidant capacity (TAC) determination, $20 \mu \mathrm{l}$ of plasma was added to $480 \mu \mathrm{l}$ of $10 \mathrm{mM}$ sodium potassium phosphate $(\mathrm{pH}=7.4)$ and $500 \mu \mathrm{l}$ of $0.1 \mathrm{mM}$ 2,2-diphenyl-1picrylhydrazyl $\left(\mathrm{DPPH}^{\bullet}\right)$. The samples were incubated in the dark for $30 \mathrm{~min}$ at RT and centrifuged $(20,000 \mathrm{~g}, 3 \mathrm{~min}$, and $20^{\circ} \mathrm{C}$ ). Then, the absorbance was monitored at $520 \mathrm{~nm} \mathrm{[10].}$ In GSH, $20 \mu \mathrm{l}$ of erythrocyte lysate treated with 5\% TCA was mixed with $660 \mu \mathrm{l}$ of $67 \mathrm{mM}$ sodium potassium phosphate $(\mathrm{pH}=8.0)$ and $330 \mu \mathrm{l}$ of $1 \mathrm{mM} 5,5$-dithiobis ( 2 nitrobenzoic acid) (DTNB). The samples were incubated in the dark at RT for 45 min and the absorbance was monitored at $412 \mathrm{~nm}$. GSH concentration was calculated relative to a calibration curve made using commercial standards [10].

Catalase (CAT) activity in the erythrocyte lysate was measured as previously described [10]. Specifically, $4 \mu \mathrm{l}$ of erythrocyte lysate (diluted 1:10) was added to $2991 \mu \mathrm{l}$ of $67 \mathrm{mM}$ sodium potassium phosphate $(\mathrm{pH}=7.4)$ and the samples were incubated at $37^{\circ} \mathrm{C}$ for $10 \mathrm{~min}$. Five microliters of $30 \%$ hydrogen peroxide $\left(\mathrm{H}_{2} \mathrm{O}_{2}\right)$ was added to the samples and the absorbance was monitored at $240 \mathrm{~nm}$ for $130 \mathrm{sec}$. CAT activity was calculated on the basis of the molar extinction coefficient of $\mathrm{H}_{2} \mathrm{O}_{2}$.

The superoxide anion radical-scavenging ability of plasma was measured using a slightly modified protocol of Ak and Gülçin, [12]. In this method, superoxide anion $\left(\mathrm{O}_{2}{ }^{--}\right)$is generated in a phenazine methosulfate and reduced nicotinamide adenine dinucleotide (PMS-NADH) system by $\mathrm{NADH}$ oxidation and it reduces the yellow dye of nitroblue tetrazolium $\left(\mathrm{NBT}^{2+}\right)$ to the blue colored formazan. More specifically, $125 \mu \mathrm{l}$ of $300 \mu \mathrm{M} \mathrm{NBT}{ }^{2+}, 125 \mu \mathrm{l}$ of $468 \mu \mathrm{M}$ $\mathrm{NADH}$, and $50 \mu \mathrm{l}$ of plasma were added into $625 \mu \mathrm{l}$ of $16 \mathrm{mM}$ Tris- $\mathrm{HCl}(\mathrm{pH}=8.0)$. The reaction is initiated by the addition of $125 \mu \mathrm{l}$ of $60 \mu \mathrm{M}$ PMS to the mixture. The samples were incubated for $5 \mathrm{~min}$ and the absorbance was monitored at $560 \mathrm{~nm}$. Plasma antioxidants are acting as inhibitors to the blue colored formazan formation. The $\mathrm{O}_{2}{ }^{--}$radical-scavenging activity was calculated according to (1):

$$
\begin{aligned}
& \text { \% Superoxide radical scavenging activity } \\
& \qquad=\left[\frac{\left(\mathrm{Abs}_{\text {control }}-\mathrm{Abs}_{\text {sample }}\right)}{\mathrm{Abs} \mathrm{sontrol}_{\mathrm{i}}}\right] \times 100,
\end{aligned}
$$

where $\mathrm{Abs}_{\text {control }}$ and $\mathrm{Abs}_{\text {sample }}$ are the absorbance values of the control and the tested sample, respectively.

In the reducing power assay, a plasma sample was dissolved in phosphate buffer $(0.2 \mathrm{M}, \mathrm{pH}=6.6)$ at different concentrations. An aliquot $(250 \mu \mathrm{l})$ of the sample solution was added to $250 \mu \mathrm{l}$ of $1 \%$ potassium ferricyanide and incubated at $50^{\circ} \mathrm{C}$ for $20 \mathrm{~min}$. The samples were cooled on ice for $5 \mathrm{~min}$. Then, $250 \mu \mathrm{l}$ of $10 \%$ TCA was added and the samples were centrifuged $\left(1700 \mathrm{~g}, 10 \mathrm{~min}\right.$, and $\left.25^{\circ} \mathrm{C}\right)$. Subsequently, $250 \mu \mathrm{l}$ of $\mathrm{dH}_{2} \mathrm{O}$ and $50 \mu \mathrm{l}$ of $0.1 \%$ ferric chloride were added to the supernatant and the samples were incubated at RT for $10 \mathrm{~min}$. The absorbance was monitored at $700 \mathrm{~nm}[13]$.

Regarding the assay for hydroxyl radical- $\left(\mathrm{OH}^{*}-\right)$ scavenging activity, $75 \mu \mathrm{l}$ of plasma dissolved in $\mathrm{dH}_{2} \mathrm{O}$ at different concentrations was added to $450 \mu \mathrm{l}$ of $0.2 \mathrm{M}$ sodium phosphate buffer $(\mathrm{pH}=7.4), 150 \mu \mathrm{l}$ of $10 \mathrm{mM}$ 2-deoxyribose, $150 \mu \mathrm{l}$ of $10 \mathrm{mM} \mathrm{FeSO}_{4}$-EDTA, $525 \mu \mathrm{l}$ of $\mathrm{dH}_{2} \mathrm{O}$, and $150 \mu \mathrm{l}$ of $10 \mathrm{mM} \mathrm{H}_{2} \mathrm{O}_{2}$. Then, the samples were incubated at $37^{\circ} \mathrm{C}$ for $4 \mathrm{~h}$. Afterwards, $750 \mu \mathrm{l}$ of $2.8 \%$ TCA and $750 \mu \mathrm{l}$ of $1 \%$ TBA were added, and the samples were incubated at $95^{\circ} \mathrm{C}$ for $10 \mathrm{~min}$. Then, the samples were cooled on ice for $5 \mathrm{~min}$, centrifuged $\left(1700 \mathrm{~g}, 10 \mathrm{~min}\right.$, and $\left.25^{\circ} \mathrm{C}\right)$, and the absorbance was monitored at $520 \mathrm{~nm}$. In each experiment, the sample without $\mathrm{H}_{2} \mathrm{O}_{2}$ was considered as blank and the sample 
TABLE 1: Delayed onset muscle soreness (DOMS) pre- and postexercise.

\begin{tabular}{|c|c|c|c|c|c|}
\hline & Pre & Immediately after & $24 \mathrm{~h}$ & $48 \mathrm{~h}$ & $72 \mathrm{~h}$ \\
\hline \multicolumn{6}{|l|}{ Trained } \\
\hline DOMSw & $1.00 \pm 0.00$ & $4.49 \pm 0.67^{*}$ & $3.52 \pm 0.48^{*}$ & $4.52 \pm 0.48^{*}$ & $3.00 \pm 0.46^{*}$ \\
\hline DOMSsq & $1.00 \pm 0.00$ & $3.58 \pm 0.37^{*}$ & $4.08 \pm 0.51^{*}$ & $4.33 \pm 0.48^{*}$ & $3.17 \pm 0.51^{*}$ \\
\hline \multicolumn{6}{|l|}{ Untrained } \\
\hline DOMSw & $1.00 \pm 0.00$ & $3.44 \pm 0.38^{*}$ & $4.21 \pm 0.44^{*}$ & $5.34 \pm 0.53^{*}$ & $4.43 \pm 0.33^{*}$ \\
\hline DOMSsq & $1.00 \pm 0.00$ & $3.44 \pm 0.50^{*}$ & $4.84 \pm 0.44^{*}$ & $5.71 \pm 0.55^{*}$ & $5.05 \pm 0.53^{*}$ \\
\hline
\end{tabular}

DOMSw: DOMS assessed during walking; DOMSsq: DOMS assessed after performing a squat movement. Values are expressed as mean \pm SEM. * Statistically significant compared with preexercise values $(p<0.05)$

without protein as control. The $\mathrm{OH}^{\bullet}$ scavenging activity was calculated according to (2):

$$
\begin{aligned}
& \text { \% Hydroxyl radical scavenging activity } \\
& \qquad=\left[\frac{\left(\mathrm{Abs}_{\text {control }}-\mathrm{Abs}_{\text {sample }}\right)}{\mathrm{Abs} \mathrm{sontrol}_{\text {l }}}\right] \times 100,
\end{aligned}
$$

where $\mathrm{Abs}_{\text {control }}$ and $\mathrm{Abs}_{\text {sample }}$ are the absorbance values of the control and the tested sample, respectively [14].

Oxidation-reduction potential (ORP) in plasma was determined by a novel method using the RedoxSYS Diagnostic System (Luoxis Diagnostics Inc., Englewood, CO, USA). Specifically, ORP is an integrated measure of the balance between the pool of oxidants (e.g., oxidized thiols, $\mathrm{O}_{2}{ }^{--}$, $\mathrm{OH}^{\circ}, \mathrm{H}_{2} \mathrm{O}_{2}, \mathrm{NO}^{\circ}$, ONOO${ }^{\circ}$, and transition metal ions) and the pool of reductants (e.g., free thiols, ascorbate, $\alpha$-tocopherol, $\beta$-carotene, and uric acid). It has been shown that this is an effective, fast, and accurate method for the determination of oxidative stress induced by an ultramarathon mountain race, eccentric exercise, and a strenuous basketball season $[6,10,15]$. The system consists of a battery-powered reader and small sensors that require limited sample manipulation, as it measures ORP within $4 \mathrm{~min}$ in $20 \mu \mathrm{l}$ of heparinized mammalian plasma samples. Static oxidation-reduction potential (sORP) value displays the integrated balance of oxidants and reductants in a sample and is expressed in millivolts $(\mathrm{mV})$. Capacity oxidation-reduction potential (cORP) is the amount of the antioxidant pool in the human body and is expressed in microcoulombs $(\mu \mathrm{C})$. High sORP values and low cORP values indicate the presence of oxidative stress [10].

2.6. Assessment of Delayed Onset Muscle Soreness (DOMS). Perceived soreness of the participants as a measure of DOMS was rated by them on a scale ranging from 1 (i.e., no pain), 5 (i.e., moderate pain), to 10 (i.e., very strong pain) during walking (DOMSw) and the squat movement (DOMSsq).

2.7. Statistical Analysis. The distribution of the biomarker values in each sample was examined by the Shapiro-Wilk test and was found not to differ significantly from normality. Data were analyzed using two-way ANOVA followed by Dunnett's test for multiple pairwise comparisons. Correlations between oxidative stress biomarkers were examined by Spearman's correlation analysis. The level of significance was set at $p<0.05$. Data are presented as mean \pm SEM. For all statistical analyses, SPSS version 20.0 (SPSS, Inc., Chicago, IL, USA) was used.

\section{Results}

3.1. Muscle Soreness. Eccentric exercise resulted in significant increases in DOMS levels of the trained group ranging between 3.49- and 4.52-fold during walking and between 3.58- and 4.33-fold after squatting. The corresponding data collected by the untrained group after walking and the squat movement increased significantly from 3.44- to 5.34-fold and from 3.44- to 5.00-fold, respectively (Table 1). Moreover, the correlation between DOMS levels and oxidative stress markers exhibited significant negative correlations between DOMS, cORP, and reducing power in the untrained group. Specifically, there was a negative correlation between DOMS squat and cORP $48 \mathrm{~h}$ postexercise while negative correlations were also obtained between DOMS walking, cORP, and reducing power at the $72 \mathrm{~h}$ postexercise time point (Table 2).

\subsection{Oxidative Stress Biomarkers}

3.2.1. Protein Oxidation. Protein carbonyl levels in the untrained group were significantly increased $48 \mathrm{~h}$ postexercise by $14.67 \%$ compared with the preexercise value and were also significantly higher compared with the corresponding results of the trained group (Table 3 ). On the contrary, protein carbonylation of the trained group was slightly, but not significantly, decreased at all time points (Table 3 ).

3.2.2. Lipid Peroxidation Measured by Spectrophotometry. TBARS levels were increased in the trained group by $10.25 \%$, $8.50 \%$, and $14.98 \%$ at 24,48 , and $72 \mathrm{~h}$, respectively, while the corresponding results in the untrained individuals revealed significant increases by $18.29 \%, 26.89 \%$, and $13.49 \%$, respectively (Table 3 ). The TBARS levels of the untrained group were significantly higher compared to the trained group $48 \mathrm{~h}$ postexercise (Table 3 ).

\subsubsection{Lipid Peroxidation Measured by Chromatography}

(1) Validation (Linearity, Precision, and Recovery). After choosing the pretreatment procedure and establishing the chromatographic conditions for the analysis, the method was validated. Firstly, a pooled human plasma sample, spiked 
TABLE 2: Statistical correlation between DOMS and the examined oxidative stress biomarkers $24 \mathrm{~h}, 48 \mathrm{~h}$, and $72 \mathrm{~h}$ postexercise in both trained and untrained groups.

\begin{tabular}{|c|c|c|c|c|c|c|c|c|c|c|c|}
\hline & PC & TBARS & TAC & GSH & CAT & sORP & cORP & SRS & $\mathrm{RP}$ & HRS & MDA \\
\hline \multicolumn{12}{|c|}{ Trained } \\
\hline \multicolumn{12}{|l|}{24 hours } \\
\hline DOMS sq. & 0.074 & 0.423 & 0.141 & 0.182 & 0.164 & 0.191 & -0.268 & -0.154 & 0.349 & 0.336 & 0.390 \\
\hline $\begin{array}{l}\text { DOMS w. } \\
48 \text { hours }\end{array}$ & 0.093 & 0.173 & 0.202 & 0.122 & 0.174 & 0.332 & -0.252 & -0.136 & .301 & -0.50 & 0.202 \\
\hline DOMS sq. & -0.272 & -0.016 & 0.311 & 0.356 & 0.012 & -0.216 & 0.060 & -0.066 & 0.011 & 0.104 & 0.059 \\
\hline $\begin{array}{l}\text { DOMS w. } \\
72 \text { hours }\end{array}$ & 0.027 & 0.061 & 0.221 & 0.217 & 0.001 & -0.284 & 0.045 & 0.023 & 0.151 & 0.050 & 0.064 \\
\hline DOMS sq. & -0.286 & -0.334 & 0.120 & 0.284 & 0.380 & -0.057 & 0.136 & 0.369 & 0.084 & 0.108 & -0.28 \\
\hline DOMS w. & -0.039 & -0.372 & 0.039 & 0.078 & 0.389 & -0.262 & 0.410 & 0.187 & 0.198 & 0.132 & -0.25 \\
\hline \multicolumn{12}{|c|}{ Untrained } \\
\hline \multicolumn{12}{|l|}{24 hours } \\
\hline DOMS sq. & -0.120 & 0.376 & -0.357 & 0.156 & 0.029 & 0.075 & -0.234 & -0.018 & -0.041 & -0.13 & 0.193 \\
\hline $\begin{array}{l}\text { DOMS w. } \\
48 \text { hours }\end{array}$ & -0.168 & 0.164 & -0.326 & 0.085 & -0.05 & -0.085 & -0.170 & -0.003 & 0.085 & -0.03 & 0.123 \\
\hline DOMS sq. & -0.202 & 0.296 & 0.070 & 0.285 & -0.306 & -0.085 & $-0.463^{*}$ & 0.176 & -0.084 & 0.301 & 0.252 \\
\hline $\begin{array}{l}\text { DOMS w. } \\
72 \text { hours }\end{array}$ & -0.050 & 0.368 & -0.281 & 0.227 & -0.352 & -0.308 & -0.330 & 0.350 & 0.053 & 0.087 & 0.312 \\
\hline DOMS sq. & -0.269 & -0.194 & -0.118 & 0.146 & -0.003 & -0.188 & -0.164 & 0.243 & 0.273 & 0.244 & -0.12 \\
\hline DOMS w. & 0.130 & 0.130 & 0.072 & 0.134 & 0.216 & 0.018 & $-0.484^{*}$ & 0.078 & $-0.440^{*}$ & 0.098 & 0.132 \\
\hline
\end{tabular}

DOMSw: DOMS assessed during walking; DOMSsq: DOMS assessed after performing a squat movement; PC: protein carbonyls; TBARS: thiobarbituric acid reactive substances (malondialdehyde measured spectrophotometrically); TAC: total antioxidant capacity; GSH: reduced glutathione; CAT: catalase; sORP: static oxidation-reduction potential; cORP: capacity oxidation-reduction potential; SRS: superoxide radical scavenging; HRS: hydroxyl radical scavenging; RP: reducing power; MDA: malondialdehyde (measured by HPLC-DAD). *Statistically significant correlation $(p<0.05)$.

TABLE 3: Percentage (\%) alterations of the oxidative stress biomarkers postexercise compared to baseline.

\begin{tabular}{|c|c|c|c|c|c|c|}
\hline & \multicolumn{3}{|c|}{ Trained } & \multicolumn{3}{|c|}{ Untrained } \\
\hline & $24 \mathrm{~h}$ & $48 \mathrm{~h}$ & $72 \mathrm{~h}$ & $24 \mathrm{~h}$ & $48 \mathrm{~h}$ & $72 \mathrm{~h}$ \\
\hline $\mathrm{PC}$ & $-0.93 \pm 3.51$ & $-7.45 \pm 4.21^{\#}$ & $-8.04 \pm 3.80$ & $8.64 \pm 4.27$ & $14.67 \pm 3.16^{*}$ & $2.32 \pm 3.16$ \\
\hline TBARS & $10.25 \pm 2.93^{*}$ & $8.50 \pm 2.85^{* \#}$ & $14.98 \pm 5.92^{*}$ & $18.29 \pm 7.86^{*}$ & $26.89 \pm 6.48^{*}$ & $13.49 \pm 6.98^{*}$ \\
\hline TAC & $1.59 \pm 1.56$ & $0.04 \pm 1.51$ & $0.91 \pm 1.92$ & $1.14 \pm 1.38$ & $1.50 \pm 1.52$ & $0.67 \pm 1.20$ \\
\hline GSH & $12.63 \pm 5.44^{*}$ & $23.09 \pm 7.17^{* \#}$ & $3.83 \pm 3.19$ & $-2.98 \pm 3.91$ & $1.11 \pm 5.47$ & $-9.64 \pm 4.75^{*}$ \\
\hline CAT & $1.82 \pm 3.68$ & $10.22 \pm 4.05$ & $4.13 \pm 4.14$ & $6.09 \pm 4.86$ & $5.75 \pm 4.58$ & $2.58 \pm 5.28$ \\
\hline sORP & $-2.11 \pm 0.73^{\#}$ & $-3.31 \pm 1.11^{\#}$ & $-0.64 \pm 1.14^{\#}$ & $4.65 \pm 1.43^{*}$ & $4.01 \pm 1.61^{*}$ & $7.45 \pm 1.45^{*}$ \\
\hline cORP & $30.57 \pm 7.02^{* \#}$ & $27.15 \pm 7.55^{* \#}$ & $15.84 \pm 8.18$ & $-9.31 \pm 6.41$ & $-4.87 \pm 7.11$ & $-8.57 \pm 11.28$ \\
\hline SRS & $12.16 \pm 3.17^{* \#}$ & $7.45 \pm 2.69^{* \#}$ & $5.79 \pm 2.79$ & $-1.16 \pm 3.21$ & $-3.95 \pm 3.67$ & $0.65 \pm 3.09$ \\
\hline HRS & $1.14 \pm 11.22$ & $-11.42 \pm 9.28$ & $15.72 \pm 13.74$ & $-9.29 \pm 6.06$ & $-12.66 \pm 9.60$ & $0.23 \pm 9.01$ \\
\hline $\mathrm{RP}$ & $3.14 \pm 2.82$ & $4.21 \pm 3.32$ & $5.74 \pm 3.22^{\#}$ & $-7.08 \pm 4.95$ & $0.13 \pm 5.41$ & $-10.37 \pm 5.58$ \\
\hline MDA & $14.07 \pm 3.21^{*}$ & $14.70 \pm 4.30^{*}$ & $21.79 \pm 3.59^{*}$ & $15.83 \pm 3.81^{*}$ & $14.55 \pm 3.71^{*}$ & $23.65 \pm 4.87^{*}$ \\
\hline
\end{tabular}

PC: protein carbonyls; TBARS: thiobarbituric acid reactive substances (malondialdehyde measured spectrophotometrically); TAC: total antioxidant capacity; GSH: reduced glutathione; CAT: catalase; sORP: static oxidation-reduction potential; cORP: capacity oxidation-reduction potential; SRS: superoxide radical scavenging; HRS: hydroxyl radical scavenging; RP: reducing power; MDA: malondialdehyde (measured by HPLC-DAD). Values are expressed as mean \pm SEM. *Statistically significant compared with preexercise values $(p<0.05)$. \#Statistically significant between trained and untrained at the same time point.

with $2,4,6,8,10$, and $12 \mu \mathrm{M}$ of MDA, and a calibration curve was obtained. A similar procedure was also followed for the determination of the aqueous curve by using the same concentrations of MDA. Linearity and reproducibility were evaluated by linear regression. The equations obtained by the least squared regression were $y=3.863 x+11.651$ for plasma curves and $y=4.4151 x-4.1043$ for aqueous curves, and the values to $R^{2}$ were 0.9952 and 0.9982 for plasma and 


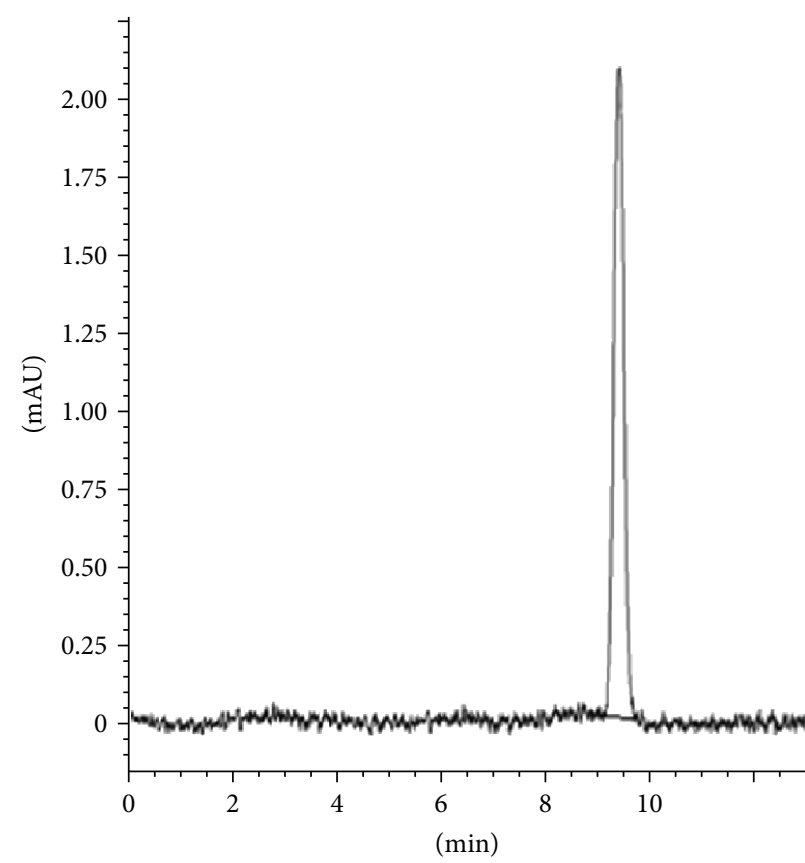

(a)

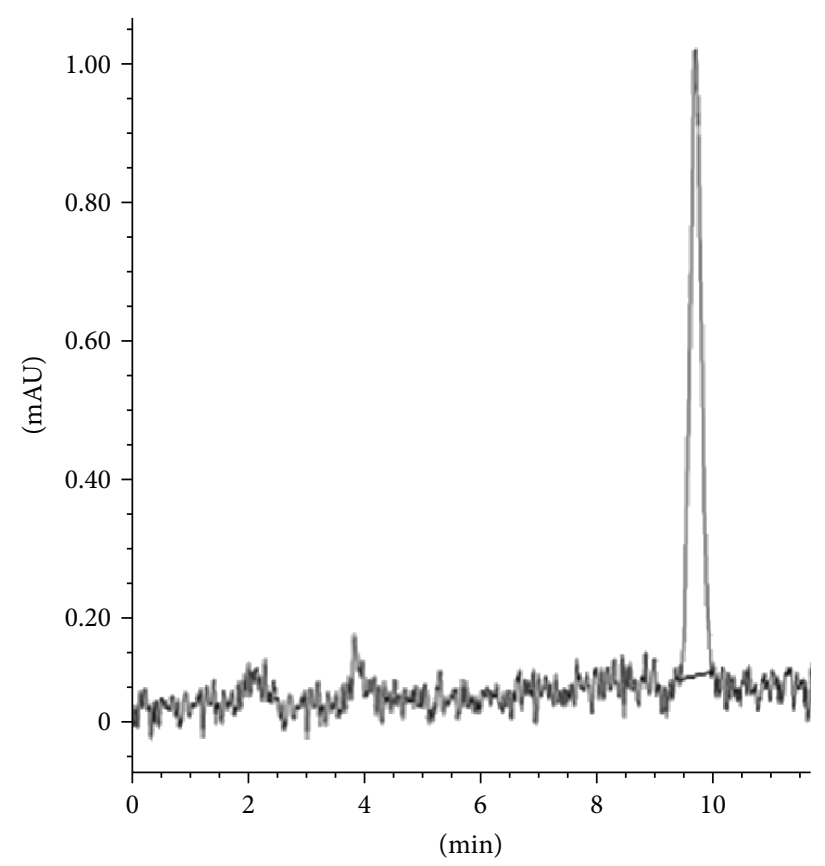

(b)

FIGURE 1: Representative chromatograms of plasma spiked with $12 \mu \mathrm{M}$ MDA (a) and a plasma sample of a volunteer containing $3.79 \mu \mathrm{M}$ MDA (b).

aqueous curves, respectively. Moreover analytical curves (i.e., peak area of each concentration from spiked plasma against area from aqueous MDA standards) exhibited an excellent linearity having a correlation coefficient more than 0.995 . The relative recovery for the MDA-TBA complex was assessed at three concentrations of $0.5,1.0$, and $1.5 \mu \mathrm{M}$, and the average recovery was counted at $98.06 \%$ (ranged from $97.54 \%$ to $98.58 \%$ ). The intra- and interday precision of this specific proposed method was determined by counting standard spiked plasma solutions. Specifically, regarding the interday precision, three different spiked plasma solutions $(0.5,1.0$, and $1.5 \mu \mathrm{M} \mathrm{MDA})$ were analyzed in triplicate for 5 consecutive days each. Intraday precision was counted by measuring a plasma solution spiked with $1.7 \mu \mathrm{M}$ of MDA plasma sample for seven times within the same day. The precisions were expressed in \% RSD and calculated at $0.43 \%$ and $0.31 \%$ for the inter- and intraday tests, respectively, which are in the range of acceptability and accuracy [16]. It is worth mentioning that the average retention time was at $9.55 \mathrm{~min}$ (Figure 1 ).

(2) Malondialdehyde Levels. As far as the chromatographic determination of MDA levels is concerned, the results were similar in both trained (i.e., MDA levels increased at all time points by $14.07 \%, 14.70 \%$, and $21.79 \%$ ) and untrained groups (i.e., MDA levels increased at all time points by $15.83 \%$, $14.55 \%$, and $23.65 \%$ ) (Table 3 ).

(3) Comparison between the MDA Concentrations Measured by Spectrophotometry and Chromatography. All tested groups exhibited a 2.5 -fold increase in MDA concentration measured by spectrophotometry (ranged from 5.5 to $9.2 \mu \mathrm{M}$ ) compared with chromatography (ranged from 2.2 to $4.7 \mu \mathrm{M}$, resp.) (Figure 2). The percentage alterations of MDA concentrations postexercise compared to preexercise were also similar between the two methods (Table 3). This similarity was also confirmed by the significant correlation between the percentage alterations of MDA values obtained by the two analytical techniques $(r=0.703, p<0.01)$ (Figure 3$)$.

3.2.4. GSH Levels. As depicted in Table 3, GSH was significantly increased in the trained group 24 and $48 \mathrm{~h}$ postexercise by $12.63 \%$ and $23.09 \%$, respectively. Furthermore, there was also a significant increase in the trained group compared with the untrained participants $48 \mathrm{~h}$ postexercise. On the contrary, GSH levels were significantly decreased in the untrained group by $9.64 \% 72 \mathrm{~h}$ postexercise compared to preexercise (Table 3 ).

3.2.5. Catalase Activity. Regarding catalase activity, no significant effects were observed (Table 3 ).

3.2.6. ORP Markers. The results from ORP marker analysis as estimated by the RedoxSYS system showed significant differences between the two groups at all time points (Table 3). In particular, the untrained group displayed significant increases at all time points postexercise by $4.65 \%$, $4.01 \%$, and $7.45 \%$, respectively, compared to preexercise, indicating induced oxidative status (Table 3 ). The cORP analysis indicated induced reductive status postexercise compared to preexercise in the trained group (Table 3). In fact, cORP levels were significantly increased by $30.57 \%$ and $27.15 \% 24$ and $48 \mathrm{~h}$ postexercise, respectively, compared with preexercise values (Table 3 ). 


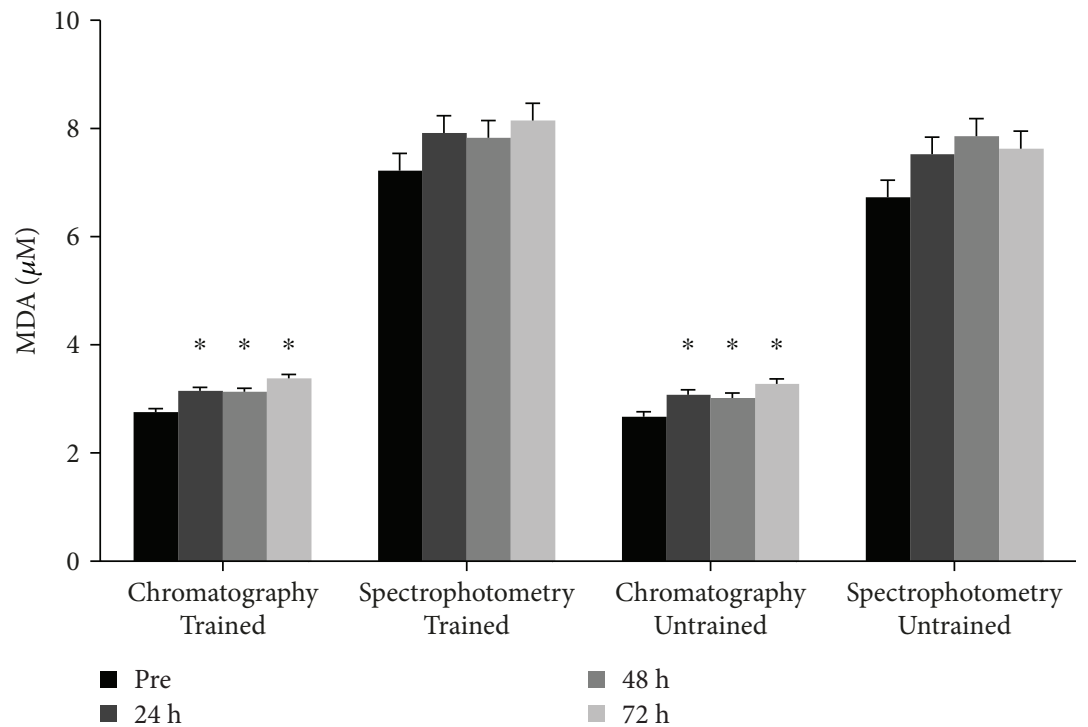

FIgURE 2: Comparison of malondialdehyde (MDA) concentrations measured chromatographically (HPLC) and spectrophotometrically (TBARS). * Statistically significant compared with preexercise value.

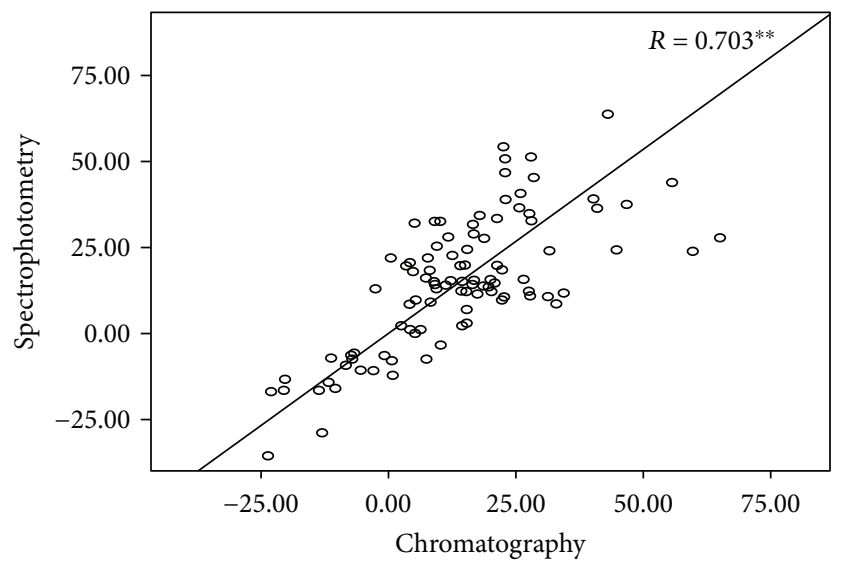

FIGURE 3: Spearman's correlation coefficient (R) and solid line for percentage (\%) alterations of MDA concentrations measured chromatographically (HPLC) and spectrophotometrically (TBARS). ** Significant correlation $(p<0.01)$.

3.2.7. Determination of Antioxidant and Free Radical Scavenging Capacity. Regarding TAC, no significant differences were observed either between pre- and postexercise or between trained and untrained groups (Table 3 ). In the reducing power assay, there was only a significant increase $72 \mathrm{~h}$ postexercise in the trained group compared to the untrained individuals (Table 3). Regarding superoxide radical-scavenging activity in the trained group, an increase 24 and 48 h postexercise by $12.16 \%$ and $7.45 \%$, respectively, compared to preexercise was displayed (Table 3 ). The participants of the trained group also exhibited increased superoxide radical-scavenging capacity compared with the untrained group 24 and $48 \mathrm{~h}$ postexercise (Table 3 ). However, no significant alteration was observed in the hydroxyl radicalscavenging capacity either between pre- and postexercise or between trained and untrained groups (Table 3 ).
Moreover, a Spearman correlation analysis was conducted for examining the possibility of a potential correlation between the above four biomarkers (Table 4). No significant correlations were observed in any of the tested groups, apart from a moderate significant correlation $(R=0.514)$ between superoxide radical-scavenging capacity and reducing power levels in the trained group.

\section{Discussion}

In the present study, the effects of eccentric exercise on oxidative stress and inflammation between trained and untrained individuals were examined. A first approach in the evaluation of exercise-induced muscle damage was the assessment of muscle pain, as eccentric exercise has been shown to cause delayed onset muscle soreness (DOMS) [6]. DOMS has been considered the major cause of reduced exercise performance, impaired muscle strength, and psychological discomfort for both trained and untrained humans [17]. In the present study, DOMS levels in the trained group were lower than those in the untrained group. It is also worth mentioning that the peak muscle soreness was detected $48 \mathrm{~h}$ postexercise in both groups, being in accordance with other studies [18]. Eccentric exerciseinduced inflammation may be the main cause of ROS production after a bout of exercise as it leads to migration of phagocytic cells to the damaged tissue. The forthcoming respiratory burst results in the production of ROS, such as superoxide and hydroxyl radicals [6]. Statistical analysis confirmed the aforementioned hypothesis, as DOMS in the untrained group displayed a significant negative correlation with CORP and reducing power, which depict the antioxidants' reserves and scavenging activity, respectively. However, a "preconditioning" of muscle during exercise may reduce susceptibility to inflammation response after performing a new bout of eccentric exercise, and consequently 
TABLE 4: Correlation analysis between superoxide radical-scavenging (SRS) activity, hydroxyl radical-scavenging (HRS) activity, reducing power (RP), and total antioxidant capacity (TAC).

\begin{tabular}{|c|c|c|c|c|c|c|c|c|c|}
\hline & \multicolumn{3}{|c|}{$24 \mathrm{~h}$} & \multicolumn{3}{|c|}{$48 \mathrm{~h}$} & \multicolumn{3}{|c|}{$72 \mathrm{~h}$} \\
\hline & HRS & SRS & $\mathrm{RP}$ & HRS & SRS & $\mathrm{RP}$ & HRS & SRS & $\mathrm{RP}$ \\
\hline \multicolumn{10}{|c|}{ Trained } \\
\hline HRS & & -0.153 & $0.514^{*}$ & & -0.081 & 0.253 & & 0.155 & 0.336 \\
\hline SRS & & & -0.107 & & & 0.137 & & & -0.068 \\
\hline TAC & 0.178 & -0.126 & 0.061 & -0.248 & 0.008 & -0.214 & -0.137 & 0.077 & -0.327 \\
\hline \multicolumn{10}{|c|}{ Untrained } \\
\hline HRS & & 0.352 & -0.117 & & -0.385 & 0.166 & & -0.412 & -0.328 \\
\hline SRS & & & -0.127 & & & -0.069 & & & 0.130 \\
\hline TAC & 0.230 & 0.325 & -0.199 & -0.007 & -0.117 & 0.346 & 0.356 & -0.069 & -0.123 \\
\hline
\end{tabular}

*Significant correlation $(p<0.05)$.

the inflammatory response is not so extended, resulting in weaker muscle pain. The latter confirms the notion regarding the relationship between inflammatory and pain response and may account for the difference in muscle pain between the two examined groups of our study [19].

As regard to protein carbonylation, it typically occurs several hours after eccentric exercise and generates a substantial amount of ROS via multiple mechanisms [20]. Our results indicated a more effective protection of proteins from oxidation (i.e., reduction of PC concentration) in the trained group compared to the untrained individuals postexercise assuring the impact of training background [19]. Interestingly, another study has shown an increase in protein oxidation levels of "nonresistance" trained women after eccentric exercise [20]. Considering that in this experiment the majority of trained individuals (17/22) were accustomed to resistance training, it seems that the type of exercise may affect the range of muscle injury and the forthcoming protein carbonylation.

Lipid peroxidation did not show any significant alterations between the tested groups when measured spectrophotometrically using the TBARS assay. However, increased MDA concentrations were observed in both groups at all time points compared with preexercise samples. This is usually observed several hours to days after acute resistance exercise probably triggered by leukocyte and macrophage infiltration and/or xanthine oxidase activation due to the ischemiareperfusion process [21]. Since the TBARS assay has received criticism due to a lack of specificity that increases the noise of the measurements [22, 23], we also performed HPLC-DAD, a more specific method for MDA determination in plasma, in order to compare these two methods. The results indicated an approximately 2.5-fold increase in the absolute values of MDA concentration measured spectrophotometrically compared with the chromatographic results in both groups. This finding confirmed that MDA is determined in a more sensitive manner by HPLC than by spectrophotometry, since in TBARS assay, TBA reacts apart from MDA with other compounds such as sugars, amino acids, and aldehydes [11]. Interestingly, a similar difference between the two performed assays has also been previously reported $[11,23]$. However, the TBARS assay exhibited a good matching with chromatography regarding the postexercise percentage alterations of MDA concentrations, a fact that was also verified by the significant correlation between the two assays (Figure 3). Therefore, regardless of the obtained overestimated absolute values, alterations of MDA concentration can be reliably described using spectrophotometry (i.e., TBARS). Thus, (3) can be used by researchers for the accurate spectrophotometric calculation of MDA concentration:

$$
\begin{aligned}
& \text { Chromatographic }[\mathrm{MDA}](\mu \mathrm{M}) \\
& \quad=0.4 \text { spectrophotometric }[\mathrm{MDA}](\mu \mathrm{M}) .
\end{aligned}
$$

Regarding GSH levels, they increased in the trained compared to the untrained individuals at all tested time points and especially $48 \mathrm{~h}$ postexercise. In that sense, it has been proposed that regular exercise induces adaptations due to the repeated activation of antioxidant genes and proteins leading to a higher antioxidant capacity and, therefore, to a more effective neutralization of ROS [2]. GSH-related antioxidant enzymes play a significant role in GSH synthesis and regeneration and, therefore, this explains the GSH increase in trained participants [24].

Similarly, ORP markers also indicated that oxidative stress was lower in the trained individuals. Specifically, sORP levels in the untrained group were found not only significantly higher postexercise compared with preexercise values but also elevated compared to the trained participants suggesting oxidative stress induction. Our group has previously reported that this marker was increased and associated with oxidative stress induction after endurance and strenuous exercise $[6,10]$. The obtained result of the cORP assay, which indicates antioxidant capacity, was also in accordance with sORP, as it was higher in the trained participants. Thus, it becomes evident that untrained individuals are more vulnerable to ROS generation and inflammation response after muscle injury. The improved capability of trained people to decrease ROS levels imply that they are better protected from exercise-induced oxidative damage.

The increased antioxidant capacity of the trained participants was also confirmed by the significant increase in $\mathrm{O}_{2}{ }^{--}$scavenging capacity postexercise compared to 
preexercise as well as compared to their untrained counterparts. According to the literature, SOD plays a predominant role in scavenging $\mathrm{O}_{2}{ }^{--}$in plasma [25]. Interestingly, studies have shown that trained individuals exhibited high SOD levels, thus coping with $\mathrm{O}_{2}{ }^{--}$more effectively [26]. Similarly, reduction of $\mathrm{Fe}$ (III) to $\mathrm{Fe}$ (II) as determined by the reducing power assay was higher in the trained in comparison with the untrained individuals. It is apparent that the concentrations of plasma antioxidant molecules, such as uric acid, $\alpha$ tocopherol, bilirubin, and ascorbic acid are elevated in individuals with an athletic background [27]. The high GSH levels in the trained group may account for their higher reducing capacity, since GSH acts as an antioxidant by donating hydrogen atoms in the regeneration of the antioxidant vitamins E and C [28]. On the other hand, no significant alterations were observed in $\mathrm{OH}^{*}$ scavenging levels after exercise compared with preexercise samples, whereas trained individuals were again more efficient in neutralizing $\mathrm{OH}^{*}$ $72 \mathrm{~h}$ postexercise compared to untrained individuals.

Finally, the lack of significant correlations between the examined biomarkers is worth mentioning (apart from RP and $\mathrm{OH}^{\bullet}$ in the trained group at $72 \mathrm{~h}$ ). This fact confirms the notion that oxidative stress induction and the following adaptations based on the activation of the antioxidant mechanisms is a complex process depending on various physiological, biochemical, and genetic factors that vary considerably between individuals [29]. This particular conclusion is very important as it suggests a personalized approach for counteracting eccentric exercise-induced oxidative stress. Undoubtedly, it suggests that a specific formulation of each person's diet, according to his oxidative status and based on supplementation with the appropriate antioxidants days after performing bouts of exercise, may lead to a faster and more efficient recovery. Regarding the present study, the nutritional intake of the participants was not thoroughly examined. However, according to their report, they did not consume higher amounts of proteins through their normal diet. Furthermore, we suggested that they should abstain from any unusual nutritional as well as antioxidant supplementation a week before, until the end of the experiment. Therefore, we believe that their nutrition did not affect our results. Nevertheless, supplementation is considered a double-edge sword, as it should only be applied in a severe oxidative stress condition after strenuous exercise. Otherwise, it can interfere with muscle adaptations and damaged-tissue regeneration [30, 31].

Taking the above data into consideration, it is clear that eccentric exercise induced reductive stress or no stress instead of oxidative stress in trained individuals, contrary to what is expected after such a demanding exercise bout. Indeed, reductive stress has also been observed by our research group in athletes who participated in top level basketball competitions as well as in individuals who have undergone a $103 \mathrm{~km}$ ultramarathon mountain race [10, 15]. Nikolaidis et al. [19] have reported that a repeated bout of lengthening contractions induced much less muscle damage and blood exercise oxidative stress than the first bout, a key information in our effort to analyze our findings. It seems therefore that trained individuals regularly performing eccentric contractions have performed muscle adaptations limiting in that way the exercise-induced inflammation and the subsequent free radical production generated by neutrophil and macrophage infiltration to the injury point [32].

In general, regularly performed exercise may lead to welldescribed adaptations of the cardiovascular and muscular system. Important responses at the intramyocellular level include increases in size and number of mitochondria as well as induction of the antioxidant enzyme activities $[33,34]$. It has been proposed that exercise causes an activation of mitogen-activated protein kinases (MAPKs: p38, ERK 1, and ERK 2) that subsequently activates nuclear factor $\kappa \mathrm{B}$ $(\mathrm{NF}-\kappa \mathrm{B})$ in rat gastrocnemius muscle and consequently the expression of important enzymes associated with defense against ROS (i.e., Mn-SOD and $\mathrm{Cu}, \mathrm{Zn}-\mathrm{SOD}, \mathrm{CAT}$, and GPX1) and adaptation to exercise [35, 36]. For example, GSH-related antioxidant enzymes including glutathione reductase (GR) and GSH synthetase are also such products of the above factors' activation [24], explaining abundantly the increase of GSH in the trained participants of our study. Similarly, the activation of the mechanisms referred above, as a result of the frequent exercise, may tone up the antioxidant status of the regularly trained individuals and therefore lead to a better protection against oxidative damage and an enhanced scavenging activity against free radicals The hypothesis regarding exercise-induced responses of the trained individuals, also relies on a study, which reported that regular exercise appears to gradually increase the adaptation levels by the repeated activation of antioxidant proteins and genes [37]. However, increased free radical production may be desired or even required for normal muscle function and/or muscle regeneration [32]. Free radicals generated by neutrophils and macrophages are crucial for removing muscle tissue that has been damaged after eccentric exercise. Furthermore, they are also important as they act as signaling molecules to regulate muscle cell growth, differentiation, and proliferation in the context of damaged tissue repair [38].

\section{Conclusion}

Previous studies of our group with respect to the individualized monitoring of exercise-induced oxidative stress have suggested that each individual is a unique biological entity and that generalized recommendations concerning recovery after exercise should be avoided. Supporting this notion, the present study demonstrated that the training background is an important factor with high impact on eccentric exerciseinduced oxidative stress and the subsequent adaptations. We expect that our findings will help the endeavor to identify the ideal approach in terms of type, duration, and intensity of conducted exercise, in conjunction to the training background of an individual and may help to better understand the phenomenon of oxidative or reductive stress after exercise. Moreover, as suggested by our work, individualized nutritional approach could help to fine-tune the recovery process and consequently improve health status and performance after eccentric exercise. 


\section{Data Availability}

All data, tables, and figures in this manuscript are original and are available upon request.

\section{Ethical Approval}

All procedures performed in this study involving human participants were in accordance with the ethical standards of the institutional and/or national research committee and with the 1964 Helsinki declaration and its later amendments or comparable ethical standards, and approval was received by the "Human Subjects Committee" of the University of Thessaly (Reference no.: 1074, date: 10/02/2016).

\section{Conflicts of Interest}

The authors had no financial, consultant, or other relations that might lead to bias or a conflict of interest. The results of the present study are presented clearly, honestly, and without fabrication, falsification, or inappropriate data manipulation.

\section{Acknowledgments}

The study was funded by the Hellenic General Secretariat for Research and Technology (GSRT) and the Hellenic Foundation for Research and Innovation (HFRI) (Grant no. 5450).

\section{References}

[1] C. E. Cooper, N. B. J. Vollaard, T. Choueiri, and M. T. Wilson, "Exercise, free radicals and oxidative stress," Biochemical Society Transactions, vol. 30, no. 2, pp. 280-285, 2002.

[2] P. Steinbacher and P. Eckl, "Impact of oxidative stress on exercising skeletal muscle," Biomolecules, vol. 5, no. 2, pp. 356-377, 2015.

[3] M. G. Nikolaidis, A. Kyparos, M. Hadziioannou et al., "Acute exercise markedly increases blood oxidative stress in boys and girls," Applied Physiology, Nutrition, and Metabolism, vol. 32, no. 2, pp. 197-205, 2007.

[4] D. H. Serravite, A. Perry, K. A. Jacobs, J. A. Adams, K. Harriell, and J. F. Signorile, "Effect of whole-body periodic acceleration on exercise-induced muscle damage after eccentric exercise," International Journal of Sports Physiology and Performance, vol. 9, no. 6, pp. 985-992, 2014.

[5] M. A. Brentano and L. F. Martins Kruel, "A review on strength exercise-induced muscle damage: applications, adaptation mechanisms and limitations," Journal of Sports Medicine and Physical Fitness, vol. 51, no. 1, pp. 1-10, 2011.

[6] D. Stagos, N. Goutzourelas, A.-M. Ntontou et al., "Assessment of eccentric exercise-induced oxidative stress using oxidation-reduction potential markers," Oxidative Medicine and Cellular Longevity, vol. 2015, Article ID 204615, 10 pages, 2015.

[7] J. Lee, A. H. Goldfarb, M. H. Rescino, S. Hegde, S. Patrick, and K. Apperson, "Eccentric exercise effect on blood oxidativestress markers and delayed onset of muscle soreness," Medicine and Science in Sports and Exercise, vol. 34, no. 3, pp. 443-448, 2002.
[8] J. Kim and J. Lee, "A review of nutritional intervention on delayed onset muscle soreness. Part I," Journal of Exercise Rehabilitation, vol. 10, no. 6, pp. 349-356, 2014.

[9] N. V. Margaritelis, A. Kyparos, V. Paschalis et al., "Reductive stress after exercise: the issue of redox individuality," Redox Biology, vol. 2, pp. 520-528, 2014.

[10] Y. Spanidis, D. Stagos, M. Orfanou et al., "Variations in oxidative stress levels in 3 days follow-up in ultramarathon mountain race athletes," Journal of Strength and Conditioning Research, vol. 31, no. 3, pp. 582-594, 2017.

[11] A. L. Spirlandeli, R. Deminice, and A. A. Jordao, "Plasma malondialdehyde as biomarker of lipid peroxidation: effects of acute exercise," International Journal of Sports Medicine, vol. 35, no. 1, pp. 14-18, 2014.

[12] T. Ak and İ. Gülçin, "Antioxidant and radical scavenging properties of curcumin," Chemico-Biological Interactions, vol. 174, no. 1, pp. 27-37, 2008.

[13] G. C. Yen and P. D. Duh, "Scavenging effect of methanolic extracts of peanut hulls on free-radical and active-oxygen species," Journal of Agricultural and Food Chemistry, vol. 42, no. 3, pp. 629-632, 1994.

[14] S.-K. Chung, T. Osawa, and S. Kawakishi, "Hydroxyl radical-scavenging effects of spices and scavengers from brown mustard (Brassica nigra)," Bioscience, Biotechnology, and Biochemistry, vol. 61, no. 1, pp. 118-123, 2014.

[15] Y. Spanidis, N. Goutzourelas, D. Stagos et al., "Variations in oxidative stress markers in elite basketball players at the beginning and end of a season," Experimental and Therapeutic Medicine, vol. 11, no. 1, pp. 147-153, 2016.

[16] H. Z. Rofael and M. S. Abdel-Rahman, "Development and validation of a high-performance liquid chromatography method for the determination of cocaine, its metabolites and ketamine," Journal of Applied Toxicology, vol. 22, no. 2, pp. 123-128, 2002.

[17] M. A. Serinken, C. Gencoglu, and B. M. Kayatekin, "The effect of eccentric exercise-induced delayed-onset muscle soreness on positioning sense and shooting percentage in wheelchair basketball players," Balkan Medical Journal, vol. 30, no. 4, pp. 382-386, 2013.

[18] J. E. Hilbert, G. A. Sforzo, and T. Swensen, "The effects of massage on delayed onset muscle soreness," British Journal of Sports Medicine, vol. 37, no. 1, pp. 72-75, 2003.

[19] M. G. Nikolaidis, V. Paschalis, G. Giakas et al., "Decreased blood oxidative stress after repeated muscle-damaging exercise," Medicine and Science in Sports and Exercise, vol. 39, no. 7, pp. 1080-1089, 2007.

[20] A. H. Goldfarb, R. J. Bloomer, and M. J. Mckenzie, “Combined antioxidant treatment effects on blood oxidative stress after eccentric exercise," Medicine and Science in Sports and Exercise, vol. 37, no. 2, pp. 234-239, 2005.

[21] N. G. Avery, J. L. Kaiser, M. J. Sharman et al., "Effects of vitamin E supplementation on recovery from repeated bouts of resistance exercise," Journal of Strength and Conditioning Research, vol. 17, no. 4, pp. 801-809, 2003.

[22] D. Grotto, L. D. Santa Maria, S. Boeira et al., "Rapid quantification of malondialdehyde in plasma by high performance liquid chromatography-visible detection," Journal of Pharmaceutical and Biomedical Analysis, vol. 43, no. 2, pp. 619-624, 2007.

[23] H. F. Moselhy, R. G. Reid, S. Yousef, and S. P. Boyle, "A specific, accurate, and sensitive measure of total plasma malondialdehyde by HPLC," Journal of Lipid Research, vol. 54, no. 3, pp. 852-858, 2013. 
[24] C. Espinosa-Diez, V. Miguel, D. Mennerich et al., "Antioxidant responses and cellular adjustments to oxidative stress," Redox Biology, vol. 6, pp. 183-197, 2015.

[25] V. Lobo, A. Patil, A. Phatak, and N. Chandra, "Free radicals, antioxidants and functional foods: impact on human health," Pharmacognosy Reviews, vol. 4, no. 8, pp. 118-126, 2010.

[26] N. Ortenblad, K. Madsen, and M. S. Djurhuus, “Antioxidant status and lipid peroxidation after short-term maximal exercise in trained and untrained humans," The American Journal of Physiology, vol. 272, 4, Part 2, pp. R1258-R1263, 1997.

[27] P. E. Reddy, S. M. Manohar, S. V. Reddy, A. R. Bitla, S. Vishnubhotla, and P. V. L. N. Srinivasa Rao, "Ferric reducing ability of plasma and lipid peroxidation in hemodialysis patients: intradialytic changes," International Journal of Nephrology \& Urology, vol. 2, no. 3, pp. 414-421, 2010.

[28] J. M. May, Z. C. Qu, R. R. Whitesell, and C. E. Cobb, “Ascorbate recycling in human erythrocytes: role of GSH in reducing dehydroascorbate," Free Radical Biology \& Medicine, vol. 20, no. 4, pp. 543-551, 1996.

[29] T. Rankinen and C. Bouchard, "Gene-physical activity interactions: overview of human studies," Obesity, vol. 16, Supplement 3, pp. S47-S50, 2008.

[30] M.-C. Gomez-Cabrera, C. Borrás, F. V. Pallardó, J. Sastre, L. L. Ji, and J. Viña, "Decreasing xanthine oxidase-mediated oxidative stress prevents useful cellular adaptations to exercise in rats," The Journal of Physiology, vol. 567, no. 1, pp. 113-120, 2005.

[31] L. L. Ji, M.-C. Gomez-Cabrera, N. Steinhafel, and J. Vina, "Acute exercise activates nuclear factor (NF)- $\kappa \mathrm{B}$ signaling pathway in rat skeletal muscle," The FASEB Journal, vol. 18, no. 13, pp. 1499-1506, 2004.

[32] I. G. Fatouros and D. Kouretas, "Exercise, oxidative stress, and inflammation," in Exercise Physiology: From a Cellular to an Integrative Approach, vol. 75, p. 245, IOS Press, 2010.

[33] I. Irrcher, P. J. Adhihetty, T. Sheehan, A. M. Joseph, and D. A. Hood, "PPAR $\gamma$ coactivator- $1 \alpha$ expression during thyroid hormone- and contractile activity-induced mitochondrial adaptations," American Journal of Physiology. Cell Physiology, vol. 284, no. 6, pp. C1669-C1677, 2003.

[34] Z. Yan, M. Okutsu, Y. N. Akhtar, and V. A. Lira, "Regulation of exercise-induced fiber type transformation, mitochondrial biogenesis, and angiogenesis in skeletal muscle," Journal of Applied Physiology, vol. 110, no. 1, pp. 264-274, 2011.

[35] L. L. Ji, M.-C. Gomez-Cabrera, and J. Vina, "Exercise and hormesis: activation of cellular antioxidant signaling pathway," Annals of the New York Academy of Sciences, vol. 1067, no. 1, pp. 425-435, 2006.

[36] M.-C. Gomez-Cabrera, E. Domenech, and J. Vina, "Moderate exercise is an antioxidant: upregulation of antioxidant genes by training," Free Radical Biology \& Medicine, vol. 44, no. 2, pp. 126-131, 2008.

[37] Z. Radak, Z. Zhao, E. Koltai, H. Ohno, and M. Atalay, "Oxygen consumption and usage during physical exercise: the balance between oxidative stress and ROS-dependent adaptive signaling," Antioxidants \& Redox Signaling, vol. 18, no. 10, pp. 1208-1246, 2013.

[38] J. Vina, C. Borras, M.-C. Gomez-Cabrera, and W. C. Orr, "Part of the series: from dietary antioxidants to regulators in cellular signalling and gene expression. Role of reactive oxygen species and (phyto)oestrogens in the modulation of adaptive response to stress," Free Radical Research, vol. 40, no. 2, pp. 111-119, 2009. 


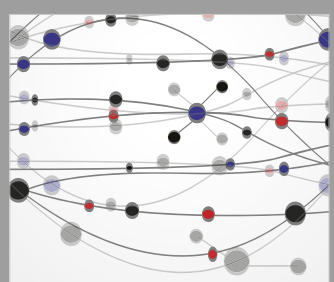

The Scientific World Journal
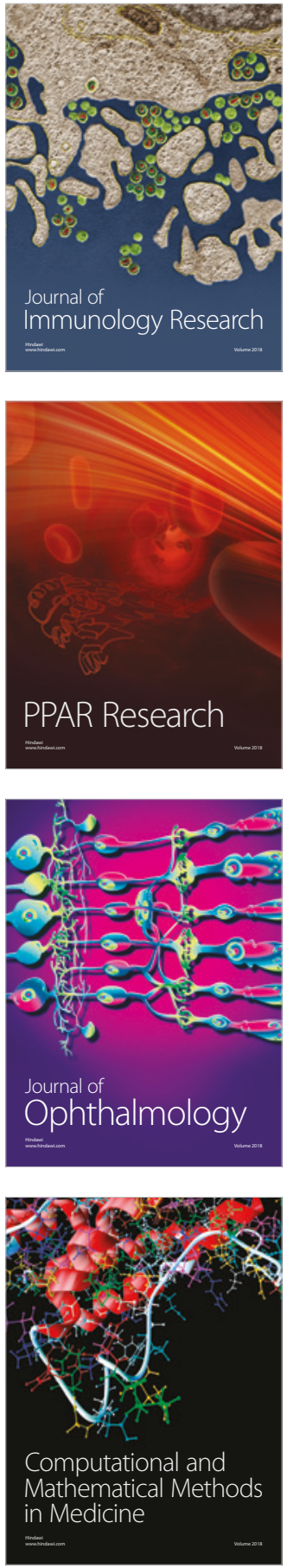

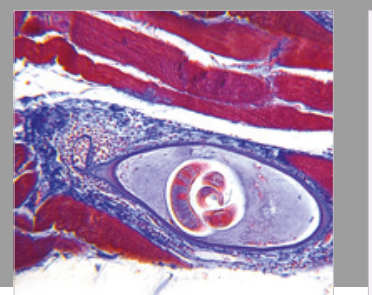

Gastroenterology Research and Practice

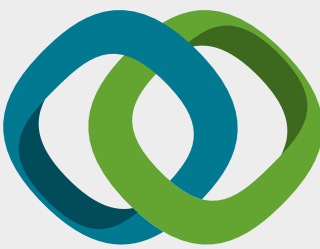

\section{Hindawi}

Submit your manuscripts at

www.hindawi.com
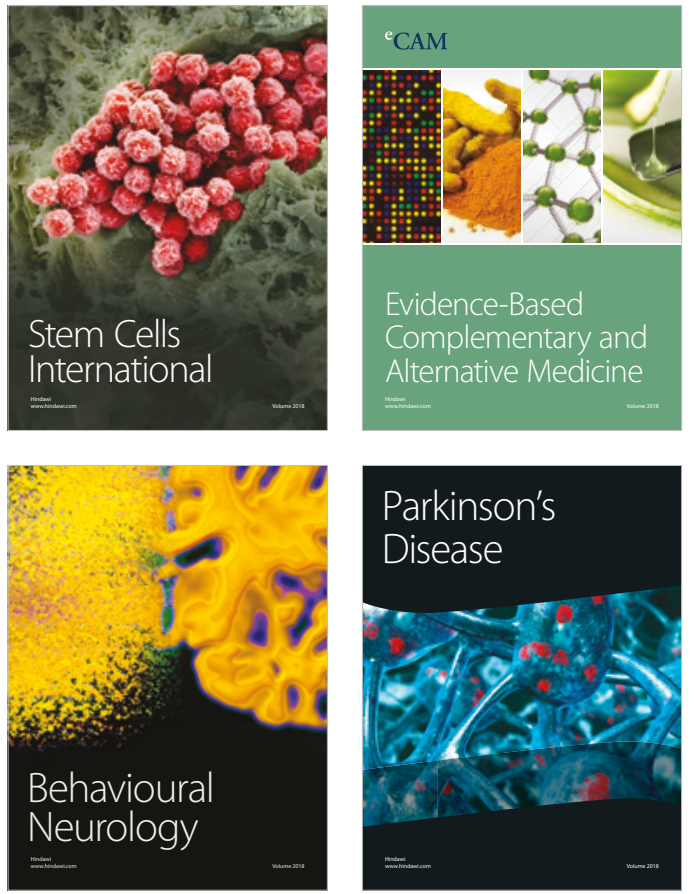

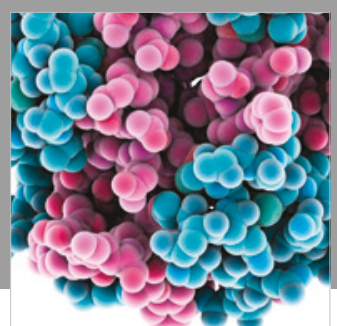

ournal of

Diabetes Research

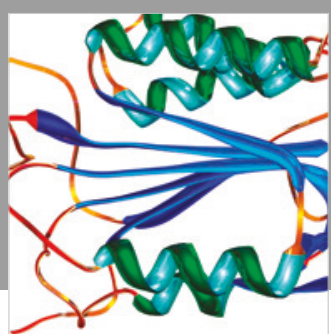

Disease Markers
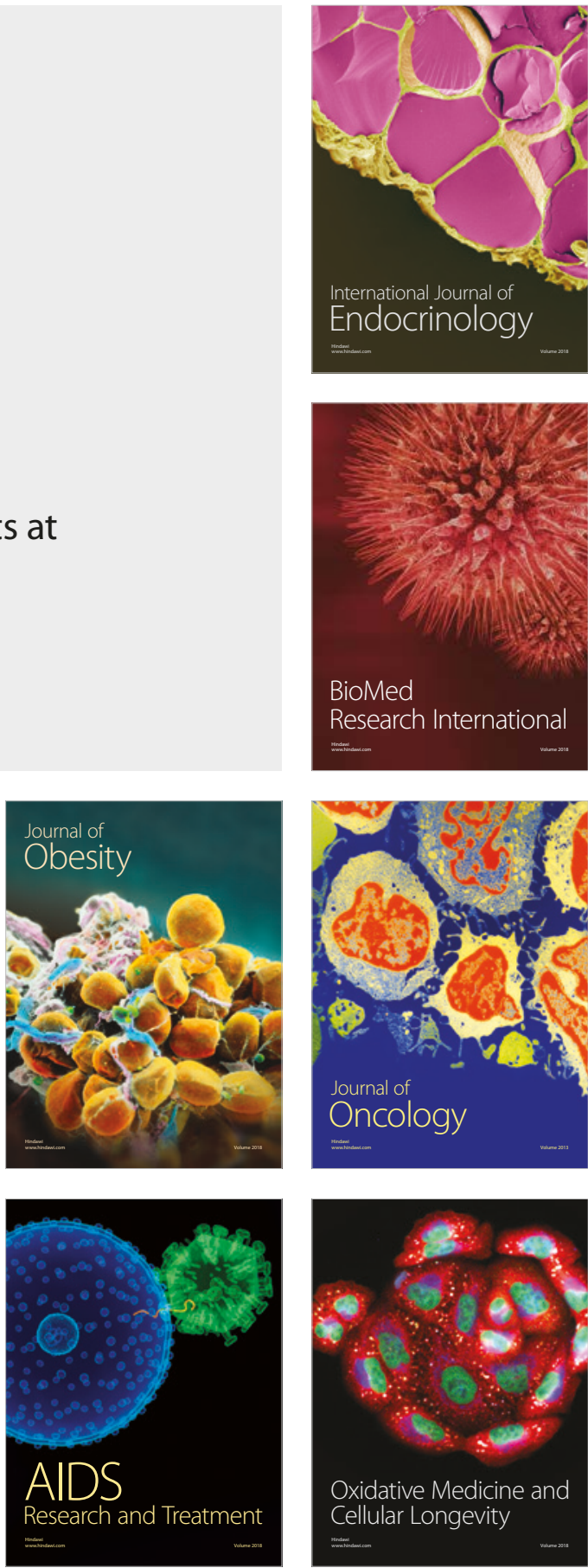